\title{
CORRECTION FACTOR FOR ACGUMULATION MEASURED BY THE THICKNESS OF THE ANNUAL LAYERS IN AN ICE SHEET
}

\author{
By J. F. NyE \\ (H. H. Wills Physics Laboratory, University of Bristol, England)
}

\begin{abstract}
The annual layers in an ice sheet become thinner by plastic deformation, and measurements of annual accumulation by the examination of cores therefore need correction. A simple correction
factor is derived.
\end{abstract}

RÉsumé. Les couches annuelles dans un ice-sheet deviennent plus minces par suite de déformations plastiques et les mesures de l'accumulation annuelle par l'examen des carottes nécessitent donc une correc-
tion. On en déduit un facteur simple de correction.

Zusammenfassung. Die Jahresschichten in einer Eistafel werden infolge plastischer Deformation dünner. Mird hergeleitet.
wiresauftrages an Eiskernen bedürfen daher einer Korrektur. Ein einfacher Korrekturfaktor

\section{INTRODUCTION}

Measurements are now being made of the annual accumulation on the Greenland Ice Sheet (Langway, I962) and in the Antarctic (Patenaude and others, 1959; Bender and Gow, I96I ; Sharp and Epstein, I962) by examining the cores extracted from deep bore holes. The net accumulation in the year when a layer was formed is deduced from the measured thickness of the layer. As a first approximation the net accumulation is simply the water-equivalent of the thickness of the layer; but, as the depth of the layer increases, a correction becomes necessary to allow for the fact that the layers are undergoing continuous plastic deformation.* Vertical plastic compression makes a given layer progressively thinner, in terms of waterequivalent, as it descends more deeply into the ice sheet. There is a corresponding plastic extension in the horizontal plane. This plastic thinning is quite distinct from the thinning in the upper layers caused by the compaction of snow into ice-for the latter gives no change in the water-equivalent of the layer thickness, nor does it cause any lateral extension.

To calculate the correction factor arising from the plastic deformation let us look at the process in more detail. A given ice element in a layer is subjected to a vertical plastic strainrate, which in general varies with time, and the total thinning is found by integrating this strain-rate. The strain-rate is itself connected, in not too obvious a way, through the mechanics of the ice sheet, with the varying accumulation rate which it is desired to deduce; moreover, since the element is moving horizontally as well as vertically, the strain-rate will presumably vary with the bed topography over which the ice passes. One approach to this seemingly complex problem is to assume that the ice sheet is on a horizontal bed and is in a steady state, that the ice has certain mechanical properties, and that the motion is two-dimensional (that is, all points move in parallel vertical planes). The problem may then be soluble, but, even so, the result is not entirely convincing because the extent to which the assumptions are fulfilled in a given case, particularly the assumption of a steady state, is not easy to assess. There was some discussion at the Obergurgl Symposium on this point after Langway's paper.

I wish to point out here that there is a simple way of expressing the correction factor which avoids many of the complications and difficulties. * Closely related problems are discussed in a forthcoming report by Bader (in press), which he has kindly
shown me before publication. 


\section{The Correction Factor}

There are two assumptions only - that there is negligible bottom melting, and that the vertical plastic strain-rate along any vertical line in the ice is uniform at any given instant. The validity of the assumptions will be discussed later. It follows from the assumptions that the (time-varying) vertical plastic strain-rate of a layer is always equal to the vertical plastic strain-rate of the ice which lies between it and the rock bed. Thus, if $l$ is the thickness of a layer, in ice-equivalent, and $h$ is its height, in ice-equivalent, above the bed,

$$
\frac{\mathrm{I}}{l} \frac{d l}{d t}=\frac{\mathrm{I}}{h} \frac{d h}{d t},
$$

ice-equivalents being used so as not to include snow and firn compaction in the strain-rate. Hence

$$
\int_{L}^{l} \frac{d l}{l}=\int_{H}^{h} \frac{d h}{h},
$$

where $L$ is the initial thickness of the layer in ice-equivalent, and $H$ is the height above the bed, in ice-equivalent, at which the layer was formed. Carrying out the integration we find

$$
\frac{l}{L}=\frac{h}{H}
$$

in other words, the total strain of a layer equals the total vertical strain of the ice beneath it. By this equation a ro per cent decrease in the height of the layer above the bed gives a ro per cent reduction in the layer thickness, and so on. Notice that time has dropped out of the equation and that shearing between the layers makes no difference. The result could hardly be simpler.

To apply equation (I) $l$ is measured from a core and $L$ is the corrected value; it obviously makes no difference whether ice-equivalents or water-equivalents are used for $l$ and $L$. Strictly, $h$ and $H$ are measured in thickness of ice-equivalent rather than as actual height above the bed, but except for the surface-layers, where the plastic correction is small anyway, the difference is insignificant. $h$ is measured at the borehole itself. $H$, on the other hand, is not the thickness at the borehole, but the thickness the ice did have at the position up-stream when and where the core was first laid down. Thus, while $l$ and $h$ are directly measurable, $H$ needs some guesswork. We cannot avoid altogether some assumption about the past behaviour of the ice sheet. The advantage of equation ( $\mathrm{I}$ ) is that it focuses the question entirely on the estimation of $H$.

For many purposes $H$ can probably be taken with sufficient accuracy as the thickness now at the point where the core was first laid down. For example, with a core $500 \mathrm{yr}$. old and a horizontal velocity of $\mathrm{io} \mathrm{m}$./yr. the point of origin would be $5 \mathrm{~km}$. up-stream, and the present depth at that point, determined seismically, could be used. If it is thought reasonable that the ice sheet has not changed in thickness by more than, say, I per cent in the last $500 \mathrm{yr}$., the correction factor is correctly estimated to that accuracy. If, alternatively, there are grounds for believing that the thickness at the point of origin has changed by a definite amount, then the correction factor can be adjusted accordingly.

To summarize, equation (I) gives the correction factor for plastic deformation of the layers under the assumptions that the vertical plastic strain-rate is always instantaneously uniform, and that there is insignificant bottom melting. The equation is valid irrespective of whether the ice sheet is in a steady state or not; it even works, for example, in the extreme case of a steady build-up of the ice cap, with no plastic deformation. No assumption of twodimensional movement is made, so that the ice can be spreading out in both lateral directions, and the effect of movement in carrying the ice over uneven bed topography is already included in the formula, in so far as the (time-varying) vertical plastic strain-rate remains. 
uniform during the movement. The problem of what assumption to make about the past behaviour of the ice sheet is entirely contained in the estimation of $H$, the height above the bed at which the core was originally laid down. In most cases it would not be difficult to estimate $H$ with ample accuracy.

\section{Validity of the Assumptions}

(i) In regard to the assumption of insignificant bottom melting, a simple calculation shows that the heat produced by bottom sliding and by the geothermal heat flux are of the same order of magnitude, and that, if both together were entirely used in melting the bottom of the ice sheet, up to about $\mathrm{I} \mathrm{cm}$. of ice per year might be melted. In fact only part of the heat flux will be used for melting, or none at all if the bed is below the melting point, and so $\mathrm{I} \mathrm{cm}$. $/ \mathrm{yr}$. is an upper limit. Bottom melting means that the downward vertical component of ice velocity at the bed is not zero, as assumed in the calculation of the correction factor, but may be up to $\mathrm{I} \mathrm{cm}$. $/ \mathrm{yr}$. The calculation thus becomes untrustworthy for layers whose rate of downward movement is as small as this. These layers would very seldom constitute more than the bottom io per cent of the thickness; in other cases the doubtful region would be even thinner or
non-existent.

(ii) The assumption that the vertical plastic strain-rate along any vertical line is uniform is frequently made, but deserves some attention.

If a model were taken which allowed no slip of the ice on the bed, the horizontal plastic extension of the lowest layer would have to be zero. Hence the vertical plastic strain-rate in the lowest layer would also have to be zero, to conserve volume. Thus, unless the vertical plastic strain-rate were everywhere zero (which would preclude a steady state) it could not, on this model, be uniform. On the other hand, with the perfectly plastic model of an ice sheet (Nye, 195I) the vertical plastic strain-rate is uniform along each vertical line.

What is the reason for this difference? Take a two-dimensional model and let $u, v$ be the velocity components in the $O x$ (horizontal) and $O y$ (vertical) directions respectively. The vertical plastic strain-rate $\partial v / \partial y=-r$, say, where $r$ is positive, and, by conservation of volume,
$\partial u / \partial x=r$. If $r$ is independent of $x$, we have

$$
u=r x, \quad(y \text { fixed })
$$

$x$ being measured from the centre of the ice sheet, where $u=0$ by symmetry. Both $u$ and $r$ will, in general, vary with $y$, and it is the $y$ dependence of $r$ that interests us. Equation (2) shows that the $y$ dependence of $r$ is exactly the same, on these assumptions, as the $y$ dependence of $u$-in other words, the velocity profile $u: y$ is also a picture of the variation of $r$ with $y$. leads to is only another way of expressing the fact that non-uniformity of $r$ in the vertical direction leads to shear between layers in the horizontal direction, and that, if we want to find the places where $r$ is most non-uniform, we must look for the layers which are shearing fastest.

The difference between the two models noted above can now be put in this way: when no slipping is allowed on the bed the $u: y$ relation is necessarily highly non-uniform, at any rate in the lower layers, and so also, therefore, is the $r: y$ relation. On the other hand, in the perfectly plastic model, the total variation in velocity between top and bottom is small compared with the average outward velocity (Nye, I95I, p. 57I), and so $r$ is effectively uniform over the depth. ( $r$ is actually exactly uniform over the depth in this model and the assumption of $r$ independent of $x$ is wrong very near the centre, but these are minor points.)

Which of the two models is more appropriate for Greenland or the Antarctic? The answer is found by looking at the temperature distribution. Both the major sources of heat, namely the geothermal and the frictional heat, are at the bottom of the ice sheets. Hence, on almost any thermal theory, steady or non-steady, the lowest layers will be the warmest. The flow law of ice depends critically upon temperature and the lowest layers are therefore the ones that shear most easily. The driving stress for horizontal shearing between layers increases linearly 
with depth. The combined result is that shearing in the lowest layers takes place much more rapidly than in the rest of the thickness. A numerical calculation confirms this (Nye, I959[a]); admittedly the calculation assumes a uniform $r$, but the result is not at all sensitively dependent on this assumption. The calculation leads to the conclusion that rapid shear strain-rates (say $>\mathrm{IO}^{-3} \mathrm{yr}^{-\mathrm{r}}$ ), if indeed they are reached at all, are confined to a bottom layer at most $100 \mathrm{~m}$. thick. Relative motion, whether between ice and ice or between ice and rock, is thus essentially concentrated in a thin bottom layer-and whether it is called very rapid shear or bottom sliding may be partly a matter of definition.

It remains to apply equation (2) and conclude that non-uniformities of $r$, in so far as they exist, are also essentially concentrated in a thin bottom layer. Thus our assumption of uniform $r$ would appear to be justified from this point of view, provided it is understood that the correction factor may not be applicable to a thin bottom layer.

But there is another way in which the assumption of uniformity in $r$ might go wrongarising from unevenness in the bed of the ice sheet. The first effect of a large-scale unevenness in the bed would be to change $r$ uniformly throughout the thickness as the ice passed over it, and if that were the only effect the correction factor ( $\mathrm{I}$ ) would still apply without any modification. Suppose, however, there were an appreciable bending of the ice-sheet about a horizontal axis as it passed over a submerged mountain. $\partial u / \partial x$ would no longer be uniform with $y$, and nor therefore would $\partial v / \partial y$. Such an effect has already been measured in a glacier (Nye, I959[b], p. 400-04) and it is readily shown that the extra strain-rate at the top and bottom is approximately $\pm \frac{1}{2} Z u d \kappa / d x$, where $Z$ is the total thickness and $\kappa$ is the curvature. To see under what conditions this non-uniform $r$ could be comparable with the uniform $r$ previously considered, which might be $5 \times 10^{-5} \mathrm{yr} .^{-1}$, put $Z=2,500 \mathrm{~m}$., $u=10 \mathrm{~m} . / \mathrm{yr}$. Then the necessary $d \kappa / d x$ is $\sim 4 \times 1^{-3} \mathrm{~km}^{-2}$, or a change in radius of curvature from, say, $25 \mathrm{~km}$. to zero in a horizontal distance of $10 \mathrm{~km}$. This is a much larger change than would normally be encountered in the smoother parts of Greenland or Antarctica, but it shows that in a mountainous region it may not always be possible to dismiss the effect completely.

The above bending effect would arise from an irregularity whose horizontal extent was much larger than the thickness of the ice sheet. The effect of smaller-scale irregularities in the bed is less easy to predict in detail, and it is very possible that they could vitiate the correction factor in the lower layers. However, if cores were taken at several different sites separated by distances at least as large as the thickness of the ice sheet, the effect of such irregularities could presumably be averaged out.

\section{MS. received II February 1963}

\section{REFERENCES}

Bader, H. In press. Criteria for measurement of strain rates in deep bore holes in polar glaciers. U.S. Cold Regions Research and Engineering Laboratory. Research Report.

Bender, J. A and Gow, A. J. I96. Deep drilling in Antarctica. Union Géodésique et Géophysique Internationale. Association Internationale d'Hydrologie Scientifique. Assemblée générale de Helsinki, 25-7-6-8 196o. Colloque sur la glaciologie antarctique, p. $\mathrm{I} 32-4 \mathrm{I}$.

Langway, C. C., jr. 1962. Some physical and chemical investigations of a 41 I meter deep Greenland ice core and their relationship to accumulation. Union Géodésique et Géophysique Internationale. Association Internationale

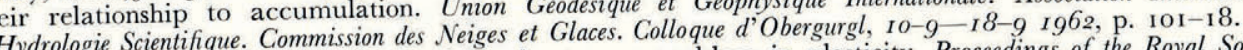

Nye, J. F. 195 I. The flow of glaciers and ice-sheets as a problem in plasticity. Proceedings of the Royal Society,

Ser. A, Vol. 207, No. rog1, p. 554-72.
Nye, J. F. 1959[a]. The motion of ice sheets and glaciers. Journal of Glaciology, Vol. 3, No. 26, p. $493-507$.

Nye, J. F. r $959[\mathrm{~b}]$. The deformation of a glacier below an ice fall. Fournal of Glaciology, Vol. 3 , No. W. Patenaude,

Patenaude, R. W., and others. 1959. Deep core drilling in ice, Byrd station, Antarctica, Technical Report 60.

E. W. Marshall and A. J. Gow. U.S. Snow, Ice and Permafrost Research Establishment. Test Antarctica. Union

Sharp, R. P., and Epstein, S. 1962. Comments on annual rates of accumulation in West Géodésique et Géophysique Internationale. Association 1 .
Glaces. Colloque d'Obergurgl, $10-9-18-91962$, p. $273-85$. 